\title{
Abnormal Meiosis Initiation in Germ Cell Caused by Aberrant Differentiation of Gonad Somatic Cell
}

\author{
Min Chen, ${ }^{1}$ Min Chen, ${ }^{1,2}$ Suren Chen, ${ }^{1,2}$ Jingjing Zhou, ${ }^{1,2}$ Fangfang Dong, ${ }^{1,2}$ \\ Zhiming Shen, ${ }^{1,2}$ Haowei Wu, ${ }^{1,2}$ Xiuhong Cui, ${ }^{1}$ and Fei Gao $\mathbb{D}^{1,2}$ \\ ${ }^{1}$ State Key Laboratory of Stem cell and Reproductive Biology, Institute of Zoology, Chinese Academy of Sciences, \\ Beijing 100101, China \\ ${ }^{2}$ University of Chinese Academy of Sciences, Beijing 100049, China
}

Correspondence should be addressed to Fei Gao; gaof@ioz.ac.cn

Received 3 May 2019; Revised 27 July 2019; Accepted 8 August 2019; Published 5 September 2019

Guest Editor: Huai-Rong Luo

Copyright (c) 2019 Min Chen et al. This is an open access article distributed under the Creative Commons Attribution License, which permits unrestricted use, distribution, and reproduction in any medium, provided the original work is properly cited.

\begin{abstract}
The interaction between germ cell and somatic cell plays important roles in germ cell development. However, the exact function of gonad somatic cell in germ cell differentiation is unclear. In the present study, the function of gonad somatic cell in germ cell meiosis was examined by using mouse models with aberrant somatic cell differentiation. In Wt $1^{R 394 W / R 394 W}$ mice, the genital ridge is absent due to the apoptosis of coelomic epithelial cells. Interestingly, in both male and female $W t 1^{R 394 W / R 394 W}$ germ cells, STRA8 was detected at E12.5 and the scattered SYCP3 foci were observed at E13.5 which was consistent with control females. In $W t 1^{-l f l o x}$; Cre-ER $R^{T M}$ mice, Wt1 was inactivated by the injection of tamoxifen at E9.5 and the differentiation of Sertoli and granulosa cells was completely blocked. We found that most germ cells were located outside of genital ridge after $W t 1$ inactivation. STRA8, SYCP3, and $\gamma \mathrm{H} 2 \mathrm{AX}$ proteins were detected in germ cells of both male and female $W t 1^{-1 f l o x} ; C r e-E R^{T M}$ gonads, whereas no thread-like SYCP3 signal was observed. Our study demonstrates that aberrant development of gonad somatic cells leads to ectopic expression of meiosis-associated genes in germ cells, but meiosis was arrested before prophase I. These results suggest that the proper differentiation of gonad somatic cells is essential for germ cell meiosis.
\end{abstract}

\section{Introduction}

In mice, primordial germ cells (PGCs) arise from extraembryonic ectoderm at approximately E6.25 and migrate to the developing genital ridge at E10.5 [1]. After several rounds of mitosis, the germ cells in male gonads enter G0/G1 arrest between E12.5 and E14.5 until initiating meiosis after birth. The female germ cells start meiosis right after sex determination at approximately E12.5, then arrest at diplotene stage of prophase I until ovulation and the meiosis is completed after fertilization [2]. The different fates of germ cells in male and female gonads are not determined by the sex chromosome constitution but by the somatic cells in the gonad [3].

Retinoic acid (RA) is the most important extrinsic factor which is indispensable for germ cell meiosis initiation. RA is synthesized in mesonephros and diffuses into adjacent gonad to induce the expression of Stra8 in germ cells of female gonads [4-7]. In male gonads, the germ cells are surrounded by Sertoli cells in testicular cords. Cytochrome P450, family 26, subfamily b, polypeptide 1 (Cyp26b1), is highly expressed in Sertoli cells during embryonic stages, which catalyzes the oxidization of RA to inactive metabolites. Therefore, the germ cells in male gonad could not access RA and initiate meiosis during embryonic stage.

As a nuclear transcription factor, Wilms tumor gene 1 $(W t 1)$ is abundantly expressed in the coelomic epithelium of the urogenital ridge and the underlying mesenchymal cells before sex determination [8]. In sex-committed gonads, $W t 1$ is specifically expressed in both Sertoli cells and granulosa cells. WT1 is originally identified as a tumor suppressor gene associated with the development of Wilms' tumors and is subsequently found to be mutated in patients with Denys-Drash syndrome (DDS) [9]. Wt1 ${ }^{R 394 W / R 394 W}$ mice are embryonic lethal and the genital ridge can not 
develop [10]. Our previous study demonstrates that in $W t 1^{R 394 W / R 394 W}$ mice, the directional migration of PGCs is not affected and most PGCs reach the mesenchyme under the coelomic epithelium at E10.5 which is consistent with control embryos [11]. We also find that when Wt1 is deleted at approximately E9.5 using Cre-ER $R^{T M}$, the development of genital ridge is not affected, whereas the differentiation of both Sertoli and granulosa cells is blocked and most genital ridge somatic cells differentiate into steroidogenic cells in both male and female gonads [12].

It has been proposed that the differentiation of gonad somatic cell plays important roles in germ cell development. However, the exact functions of somatic cells are still unclear. In this study, the function of somatic cell on germ cell meiosis is examined by using genital agenesis $\left(W t 1^{R 394 W / R 394 W}\right.$ ) and somatic aberrantly differentiated ( $W t 1^{- \text {fflox }} ; \mathrm{Cre}-E R^{T M}$ ) mouse models. We find both male and female germ cells start to express STRA8, but no germ cells at prophase I are observed. Our study demonstrates that the meiosis initiation of germ cell is accurately regulated by somatic factors.

\section{Materials and Methods}

2.1. Mice. All animal work was carried out in accordance with institutional animal care and the use committee regulations of Institute of Zoology, CAS. All mice were maintained in a C57BL/6;129/SvEv mixed background. The mouse strain carrying the $W t 1^{R 394 W}$ point mutation was generated in Dr. Vicki Huff's laboratory [10]. Wt $1^{R 394 W / R 394 W}$ mice were obtained by crossing male and female $W t 1^{+/ R 394 W}$ mice. $W t 1^{-1 f l o x}$; Cre-ER ${ }^{T M}$ offspring were obtained by crossing $W t 1^{\text {floxlflox }}$ mice with $W t 1^{+/-}$and Cre-ER ${ }^{T M}$ transgenic mice. DNA isolated from adult tails and fetal tissues was used for genotyping. Pregnant $W_{t} 1^{\text {flox/flox }}$ females were injected with Tamoxifen (Sigma-Aldrich) intraperitoneally at a dose of $6 \mathrm{mg} / 40 \mathrm{~g}$ body weight at E9.5 to induce Cre activity as described previously [12]. Wt $1^{\text {flox/flox }}$ and $W t 1^{-1 f l o x}$ embryos were used as controls.

2.2. Organ Culture. The experiment of organ culture was performed as described previously $[13,14]$. In brief, pregnant $W t 1^{\text {flox/flox }}$ females were injected with tamoxifen at E9.5. The gonads with mesonephroi were dissected from control and $W t 1^{-1 f l o x} ; C r e-E R^{T M}$ embryos at E13.5, placed on agarose stands $\left(1.5 \% w / v\right.$, in 24 -well plates), and cultured at $37^{\circ} \mathrm{C}$ and $5 \% \mathrm{CO}_{2}$. After 3 days of culture, the gonads were fixed in $4 \%$ PFA for further analysis.

2.3. Tissue Collection and Histological Analysis. Control and Wt1-inactivated embryos were collected immediately following euthanasia of pregnant mice. Gonads with mesonephroi were dissected in PBS, fixed in 4\% paraformaldehyde for up to $24 \mathrm{hrs}$, stored in $70 \%$ ethanol, and embedded in paraffin. Then, tissue sections of $5 \mu \mathrm{m}$ thickness were cut and mounted on glass slides.

2.4. Immunofluorescence Analysis and TUNEL Assay. Tissue sections were deparaffinized, rehydrated, and subjected to antigen retrieval. After blocking in 5\% donkey serum in $0.3 \%$ Triton X-100 for $1 \mathrm{hr}$, the sections were incubated with primary antibodies for $1.5 \mathrm{hrs}$ and the corresponding FITCconjugated and $\mathrm{Cy}^{\mathrm{TM}} 3$-conjugated secondary antibodies $(1: 150$ and $1: 300$, respectively, Jackson) for $1 \mathrm{hr}$ at room temperature. The following dilutions of primary antibodies were used: STELLA (1:200, Santa Cruz, sc-67249), GATA4 (1:300, Santa Cruz, sc-1237), STRA8 (1:200, Abcam, ab49405), SYCP3 (1:200, Abcam, ab15093), $\quad \gamma \mathrm{H} 2 \mathrm{AX}$ (1:200, Millipore, 05-636), DAZL (1:100, AbD Serotec, MCA2336), and MVH (1:500, Abcam, ab13840). After three washes in PBS, the sections were counterstained with DAPI to label the nuclei. The images were captured with a confocal laser scanning microscope (Carl Zeiss Inc., Thornwood, NY). TUNEL assay was conducted using the DeadEnd Fluorometric TUNEL system (Promega, G3250) as recommended.

2.5. Quantitative Reverse Transcription PCR. Gonads of E13.5 embryos were used to extract total RNA using a Qiagen RNeasy kit following manufacturer's instructions. The relative expression level was calculated using the formula $2^{-\Delta \Delta C T}$. Hprt1 was used as an endogenous control. The primers used were listed as follows: Stra 8 sense, CTCCTC CTCCACTCTGTTGC, antisense, GCGGCAGAGACAAT AGGAAG; Sycp3 sense, AGAAATGTATACCAAAGCTTC TTTCAA, antisense, TTAGATAGTTTTTCTCCTTGTTCC TCA; Rec 8 sense, CTACCTAGCTTGCTTCTTCCCA, antisense, GCCTCTAAAAGGTGTCGAATCTG; and Dmc1 sense, CCCTCTGTGTGACAGCTCAAC, antisense, GGTC AGCAATGTCCCGAAG.

2.6. Chromosome Spread and Immunofluorescence. After culture for three days, the gonads were incubated in hypotonic extraction buffer ( $30 \mathrm{mM}$ Tris, $\mathrm{pH} 8.2 ; 50 \mathrm{mM}$ sucrose; $17 \mathrm{mM}$ trisodium citrate dihydrate; $5 \mathrm{mM}$ EDTA; $0.5 \mathrm{mM}$ DTT; and $0.5 \mathrm{mM}$ PMSF) for $45 \mathrm{mins}$ at room temperature. After hypotonic treatment, $100 \mu \mathrm{l}$ sucrose $(100 \mathrm{mM})$ was added and cell suspension was pipetted up and down for several times. APES treated slides were coated with $1 \%$ paraformaldehyde containing $0.15 \%$ Triton X. $10 \mu \mathrm{l}$ cell suspension was dispersed to the slide containing a layer of paraformaldehyde. Slides were placed in a humid chamber for at least $6 \mathrm{hrs}$ at room temperature, then allowed to air dry and stored at $-80^{\circ} \mathrm{C}$ until use.

The slides were washed in $0.4 \%$ Kodak Photo-Flo 200 for 4 min and $0.1 \%$ Triton X-100 in PBS for three times, blocked in $200 \mu \mathrm{l}$ blocking buffer (3\% nonfat milk in PBST) for $1 \mathrm{hr}$ at room temperature, followed by an overnight incubation with primary antibody at $4^{\circ} \mathrm{C}$ and the corresponding FITCconjugated and $\mathrm{Cy}^{\mathrm{TM}_{3}}$-conjugated secondary antibodies for $1 \mathrm{hr}$. After three washes in PBS, the sections were analyzed with a confocal laser scanning microscope (Carl Zeiss Inc., Thornwood, NY).

2.7. Statistical Analysis. Experiments were repeated at least three times. Three to five control, Wt1-mutant or Wt1-deficient male or female embryos at each time point were used for immunostaining. For gonad culture, at least 4 pairs of male or female gonads of each genotype were used. For real-time PCR, 3 pairs of gonads of the same genotype were pooled and three independent pools were used for RNA 


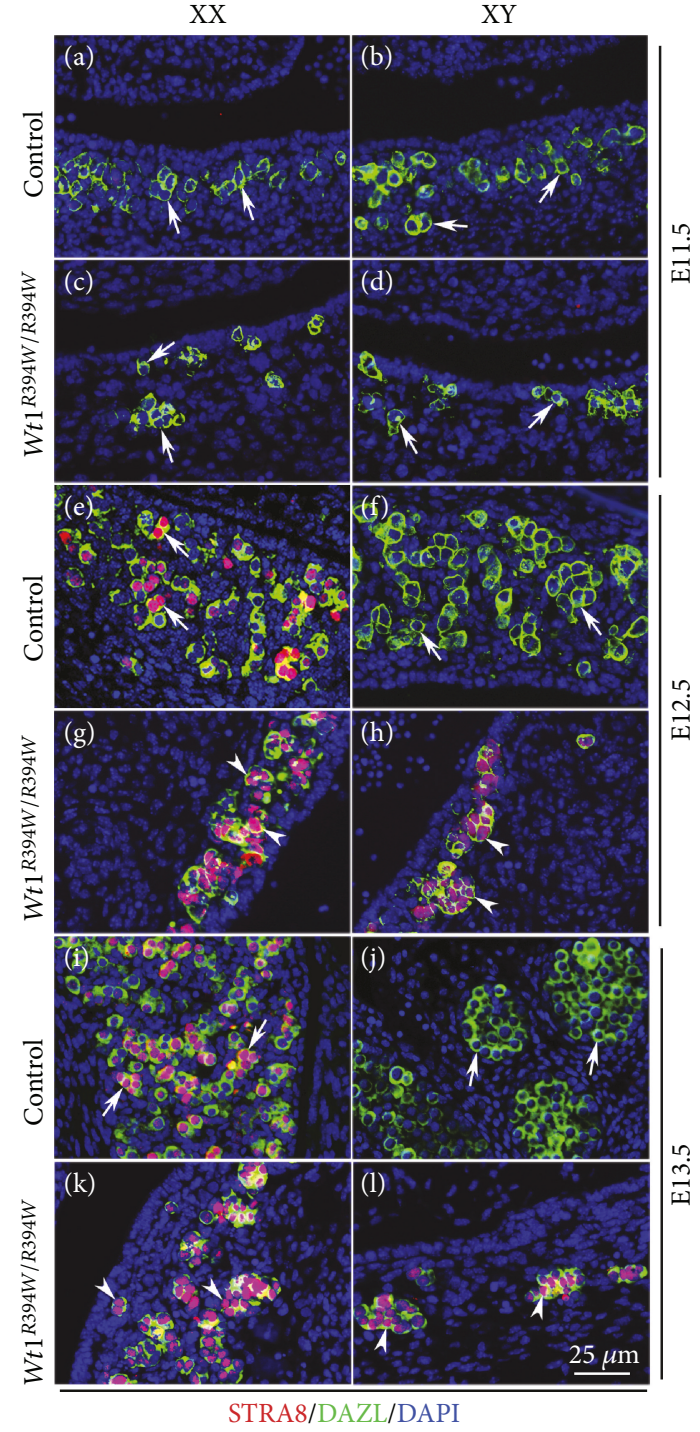

FIGURE 1: STRA8 was expressed in germ cells of both male and female $W t 1^{R 394 W / R 394 W}$ mice at E12.5 and E13.5. STRA8/DAZL double-staining experiment was performed with control $\left(W t 1^{+/ R 394 W}\right)$ and $W t 1^{R 394 W / R 394 W}$ embryos at E11.5 (A-D), E12.5 (E-H), and E13.5 (I-L). Germ cells were labeled with DAZL (green). DAPI (blue) was used to stain the nuclei. The arrowheads point to STRA8-positive germ cells in $W t 1^{R 394 W / R 394 W}$ gonads. The gender of the embryos was confirmed with PCR using Sry primers.

preparation. The results are presented as the mean \pm SEM. Student's $t$-test was used to analyze the data. Probability values of $<0.05$ were considered as significant.

\section{Results and Discussion}

3.1. STRA8 Was Expressed in Both Male and Female Germ Cells of Wt1 ${ }^{R 394 W / R 394 W}$ Mice. Our previous study demonstrates that the genital ridge is absent in $W t 1^{R 394 W / R 394 W}$ mice due to the apoptosis of coelomic epithelial cells. However, the migration of PGCs is not affected and most germ cells arrive at position where genital ridge is formed [11]. To examine whether the differentiation of germ cells is affected in the

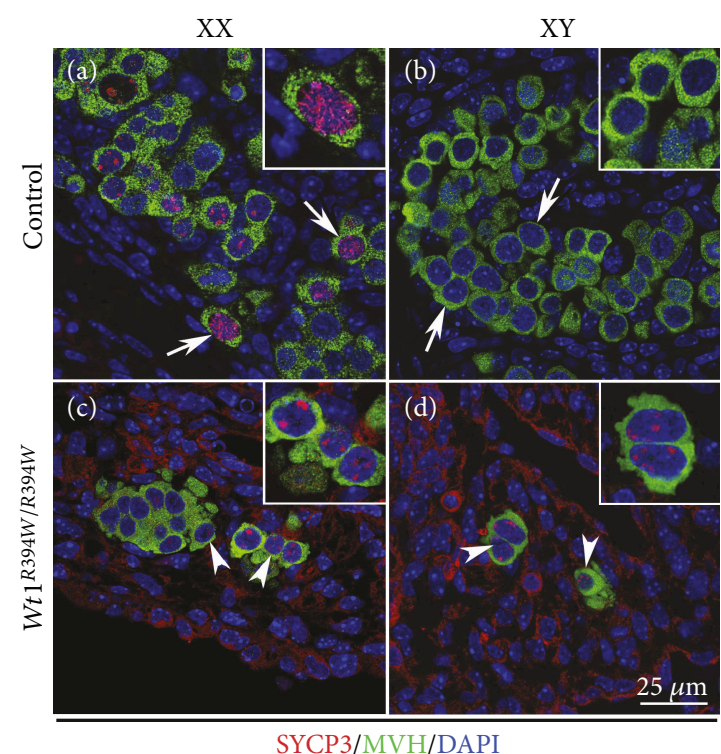

FIGURE 2: SYCP3 was expressed in germ cells of both male and female $W t 1^{R 394 W / R 394 W}$ gonads at E13.5. SYCP3/MVH double-staining experiment was performed with control $W t 1^{+/ R 394 W}(\mathrm{~A}, \mathrm{~B})$ and $W t 1^{R 394 W / R 394 W}$ (C, D) embryos at E13.5. Germ cells were labeled with MVH (green). DAPI (blue) was used to stain the nuclei. The arrowheads point to SYCP3-positive germ cells in Wt1 ${ }^{\text {R394W/R394W }}$ gonads. The gender of the embryos was confirmed with PCR using Sry primers.

absence of gonad somatic cells in $W t 1^{R 394 W / R 394 W}$ mice, the expression of meiotic genes STRA8 and SYCP3 was analyzed by immunofluorescence. As shown in Figure 1, STRA8 was expressed in germ cells of control ovaries at E12.5 (Figure 1A), and more positive germ cells were observed at E13.5 (Figure 1I). No STRA8 protein was detected in germ cells of control testes at E12.5 and E13.5 (Figure 1B, F, and J). In $W t 1^{R 394 W / R 394 W}$ mice, STRA8positive germ cells were observed in both female (Figure $1 \mathrm{G}$ and $\mathrm{K}$ ) and male gonads (Figure $1 \mathrm{H}$ and L) at E12.5 and E13.5. SYCP3 (synaptonemal complex protein 3), a lateral component of the synaptonemal complex, was first detected in control female germ cells at E13.5 (Figure 2A), but not in control male germ cells (Figure 2B). A few MVH/SYCP3 double-positive germ cells were noted in both male (Figure 2D) and female (Figure 2C) $W t 1^{R 394 W / R 394 W}$ gonads. In mammals, the timing of germ cell entry into meiosis is different between male and female. Female germ cell initiates meiosis right after sex determination. By contrast, male germ cell will not start meiosis during embryonic stage. Retinoic acid (RA) is a major extrinsic factor for germ cells to enter meiosis $[15,16]$. Stra 8 is a gatekeeper gene for meiosis initiation which is expressed in germ cells in response to RA induction [3, 17]. In male gonad, meiosis is suppressed by RA-degrading enzyme CYP26b1 secreted from Sertoli cells during embryonic stage. In the present study, STRA8 and SYCP3 proteins were expressed in germ cells of both male and female $W t 1^{R 394 W / R 394 W}$ mice. These results indicated that RA is sufficient to induce STRA 8 and SYCP3 expression in the absence of gonad somatic cells in both male and female gonads. 


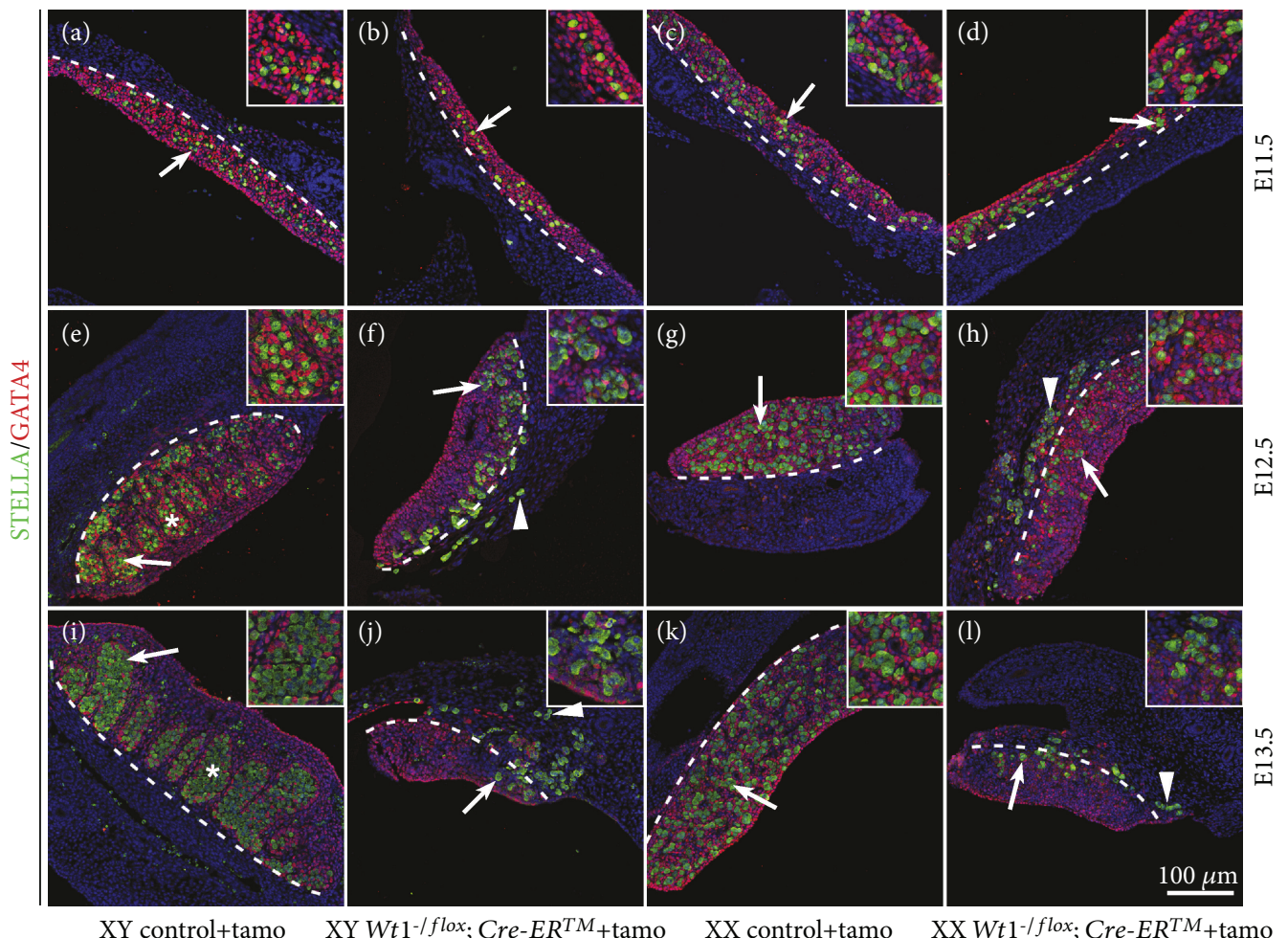

Figure 3: The location of germ cells was disrupted in $W t 1^{- \text {fflox }}$; Cre-ER $R^{T M}$ gonads. Wt $1^{\text {flox/flox }}$ females were crossed with $W t 1^{- \text {fllox }}$; $C r e-E R^{T M}$ mice and the pregnant females were injected with tamoxifen at E9.5 to induce Cre activity. Wt $1^{\text {flox/flox }}$ and $W t 1^{-/ f l o x}$ embryos were used as controls. Germ cells were labeled with STELLA (green, white arrows), and gonad somatic cells were labeled with GATA4 (red). The nuclei were stained in blue using DAPI. The dotted line denotes the border between the gonads and mesonephros. The arrowheads point to germ cells at the boundary between gonads and mesonephros. The gender of the embryos was confirmed with PCR using Sry primers. *Testicular cords.

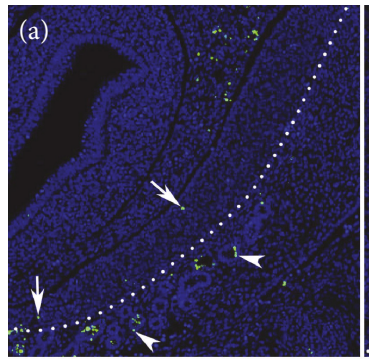

XY control

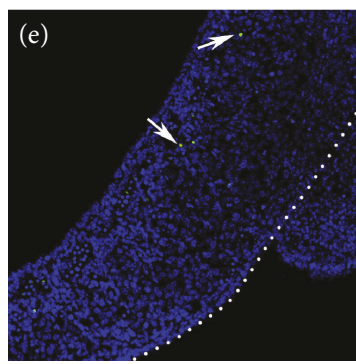

$\mathrm{XY}$ control+tamo

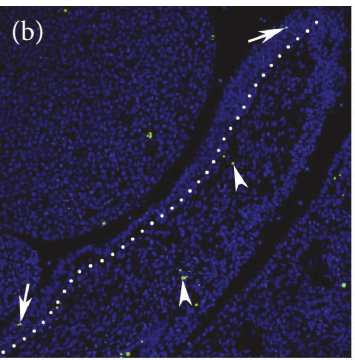

XY $W t 1^{R 394 W / R 394 W}$

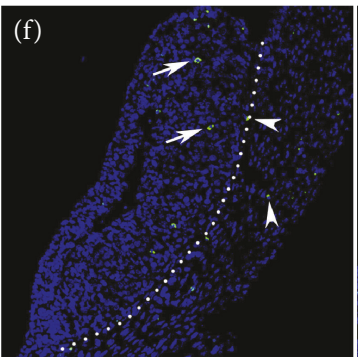

$\mathrm{XY} W t 1^{-/ \text {flox}} ;$ Cre-ER $R^{T M}+\operatorname{tamo}$

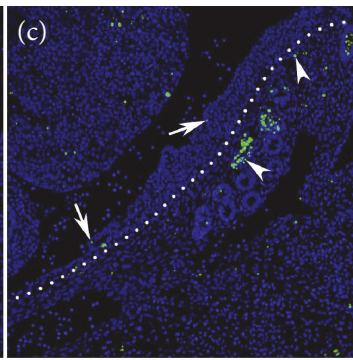

XX control

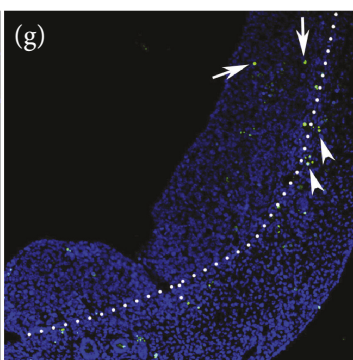

XX control+tamo

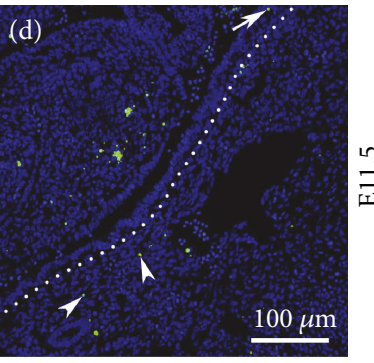

XX $W t 1^{R 394 W / R 394 W}$

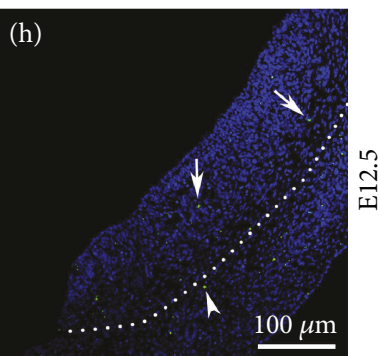

XX Wt1-/flox; Cre-ER $R^{T M_{+}}$tamo

FIGURE 4: The number of apoptotic cells was not increased in Wt1-inactivated gonads. TUNEL assay was conducted in gonads of $W t 1$ mutant $\left(\mathrm{A}, \mathrm{C}: W t 1^{+/ R 394 W} ; \mathrm{B}, \mathrm{D}: W t 1^{\text {R394W/R394W }}\right.$ ) and $W t 1$ knockout $\left(\mathrm{E}, \mathrm{G}: W t 1^{\text {floxiflox }}\right.$ or $W t 1^{-1 \text { flox }}$; F, H: Wt1 ${ }^{-1 \text { flox }}$; Cre-ER ${ }^{T M}$ ) mice. Arrows and arrowheads point to apoptotic cells (green) in gonads and mesonephros, respectively. The nuclei were stained in blue using DAPI. The dotted line denotes the border between the gonads and mesonephros. The gender of the embryos was confirmed with PCR using Sry primers. 

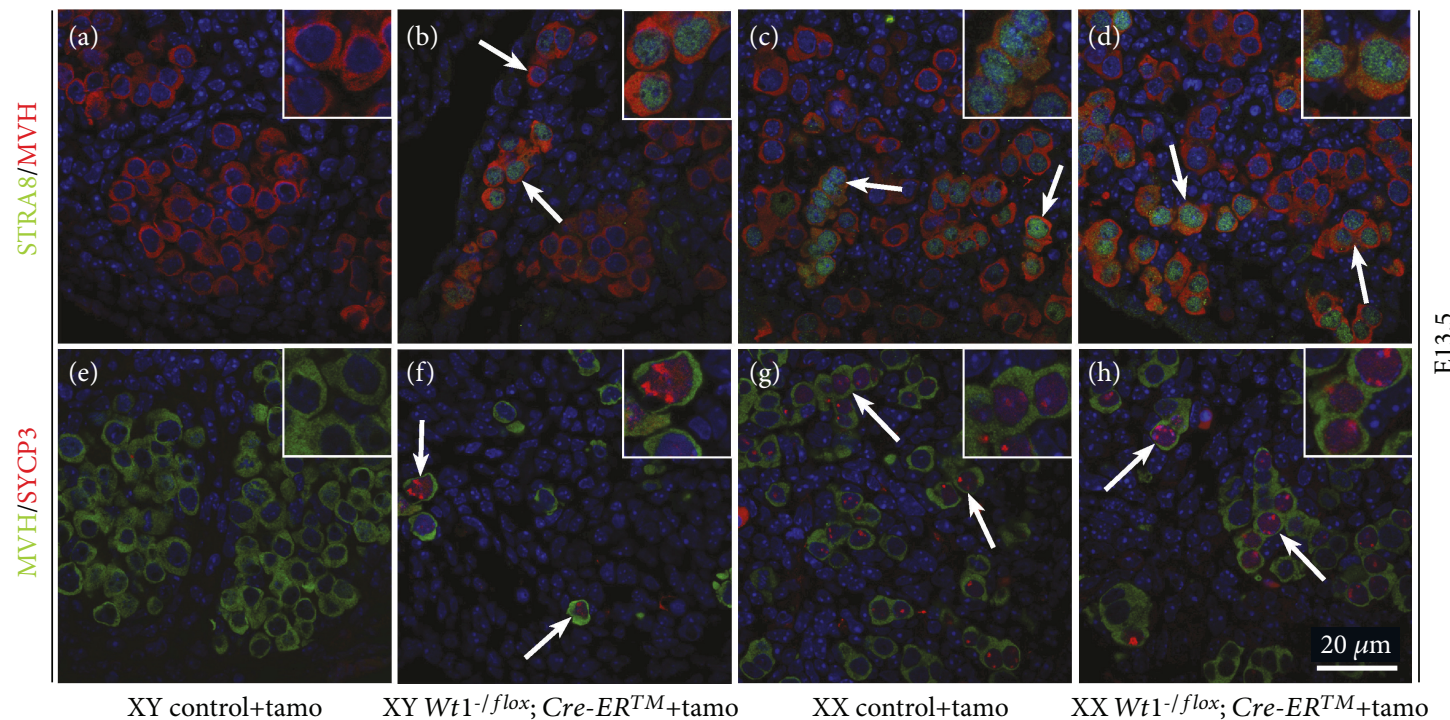

$\stackrel{\stackrel{n}{m}}{\stackrel{m}{19}}$

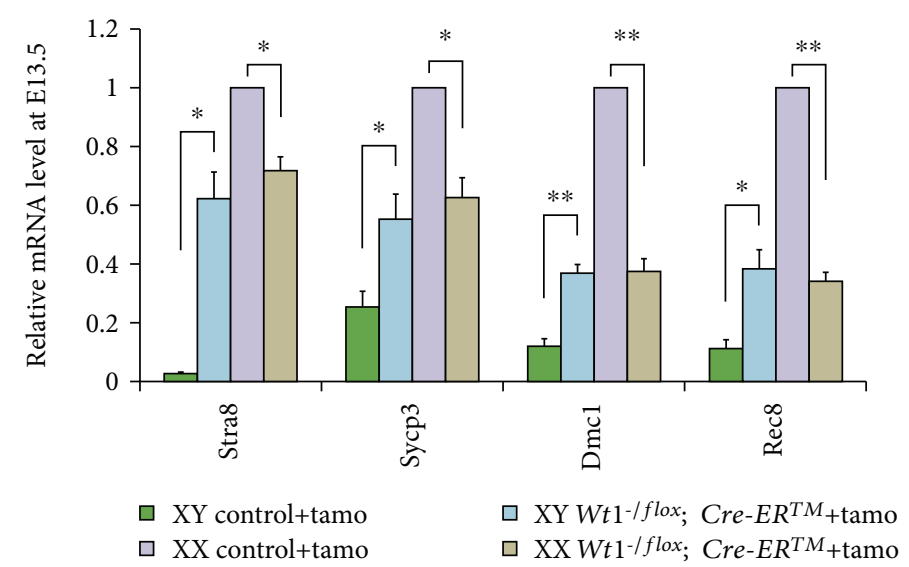

(i)

FIGURE 5: The meiotic genes were expressed in germ cells of both male and female $W t 1^{- \text {fflox }}$; Cre-ER ${ }^{T M}$ mice after tamoxifen induction. $W t 1^{\text {flox/flox }}$ females were crossed with $W t 1^{-1 f l o x}$; Cre-ER ${ }^{T M}$ mice, and the pregnant females were injected with tamoxifen at E9.5 to induce Cre activity. Wt $t^{\text {flox flox }}$ and $W t 1^{-1 \text { flox }}$ embryos were used as controls. A-H: immunofluorescence analysis of STRA8/MVH (A-D) and SYCP3/MVH (E-H) in control and Wt1 ${ }^{-1 f l o x}$; Cre-ER $R^{T M}$ embryos at E13.5. Germ cells were labeled with MVH. DAPI (blue) was used to stain the nuclei. The arrows point to double-positive germ cells. I: real-time PCR analysis of Stra8, Sycp3, Dmc1, and Rec8 in control and $W t 1^{-f f l o x}$; Cre-ER $R^{T M}$ embryos at E13.5. Hprt1 was used as an endogenous control. The data are presented as mean \pm SEM. ${ }^{*} P<0.05 ;{ }^{* *} P<0.01$.

3.2. The Location of Germ Cells in Genital Ridge Was Disrupted when Wt1 Was Inactivated at E9.5. To further investigate the functions of somatic cells in germ cell development, Wt1 was deleted at later stage using a tamoxifeninducible Cre $\left(\mathrm{Cre}-E R^{T M}\right)$ mice. Wt1 flox/flox females were crossed with $W t 1^{- \text {flox }}$; Cre-ER ${ }^{T M}$ males, and the pregnant females were injected with tamoxifen at E9.5 and the embryos were collected from E11.5 to E13.5. STELLA and GATA4 were used to label germ cells and somatic cells, respectively. As shown in Figure 3, the size of Wt1-deficient gonads $(\mathrm{F}, \mathrm{H}, \mathrm{J}$, and $\mathrm{L}$ ) was smaller than control gonads (E, G, I, K) at E12.5 and E13.5. In control males, the testicular cords were well organized at E12.5 and E13.5 (Figure 3E and $\mathrm{I}$, asterisks). By contrast, no testicular cords were observed in $W t 1^{-1 f l o x}$; Cre-ER ${ }^{T M}$ male gonads (Figure $3 \mathrm{~F}$ and J), suggesting that $W t 1$ is required for the testicular formation which is consistent with our previous study [18]. In control female gonads, germ cells were scattered inside the genital ridge (Figure $3 \mathrm{G}$ and $\mathrm{K}$, white arrows). Interestingly, only a small portion of the germ cells were located inside the genital ridge of $W t 1^{- \text {Iflox }}$; Cre-ER $R^{T M}$ mice at E12.5 and E13.5, and most germ cells were observed at the boundary between gonads and mesonephros (white dotted line). Our previous study has demonstrated that Wt1 directs the lineage specification of Sertoli and granulosa cells. Without Wt1 expression, the somatic cells differentiate into steroidogenic cells instead of supporting cells [12]. In this mouse model, Wt1 was deleted at E10.5 approximately. The abnormal differentiation of supporting cells became evident after E11.5 ${ }^{12}$ and the mislocation of germ cells in $W t 1^{- \text {flox }}$; Cre-ER ${ }^{T M}$ mice was observed at E12.5 and E13.5. Based on these results, we speculated that structure support or paracrine signals released from somatic cells are indispensable for the precise location of germ cells in the gonads. However, the detailed regulatory mechanism 


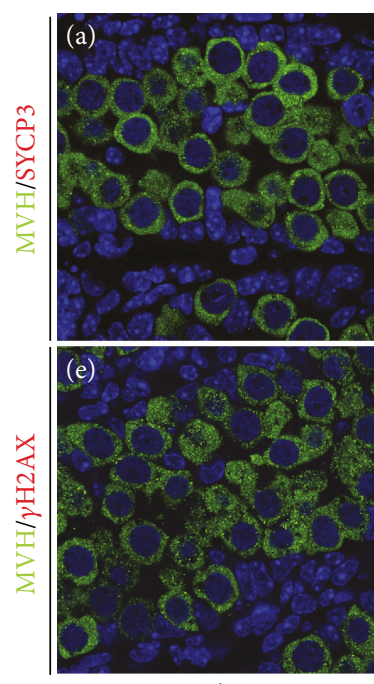

$\mathrm{XY}$ control+tamo

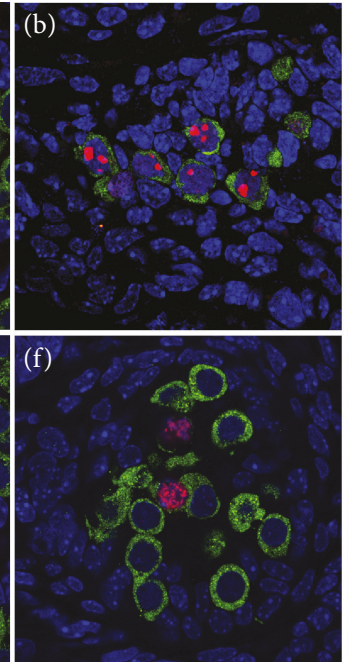

XY Wt1-/flox; Cre-ER $R^{T M}+\operatorname{tamo}$

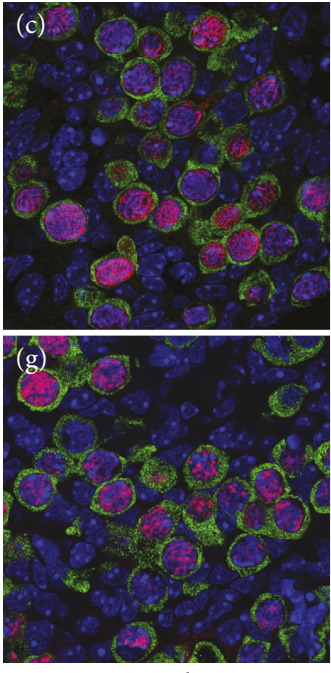

XX control+tamo

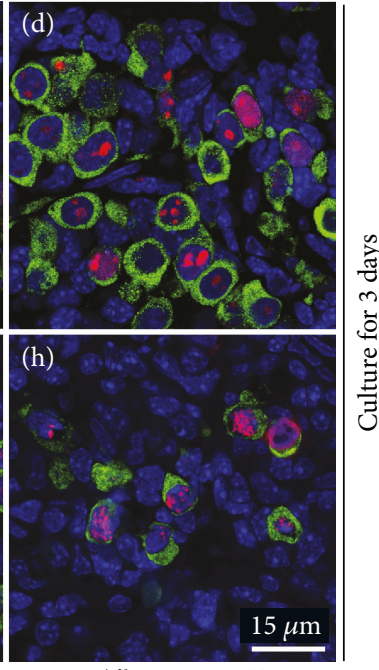

XX Wt1-/flox; Cre-ER ${ }^{T M}+\operatorname{tamo}$

Figure 6: The meiosis was blocked in germ cells of $W t 1^{- \text {fflox }}$; Cre-ER $R^{T M}$ gonads. Wt $1^{\text {floxlflox }}$ females were crossed with $W t 1^{-I f l o x}$; $C r e-E R^{T M}$ mice, and the pregnant females were injected with tamoxifen at E9.5 to induce Cre activity. Control $\left(W t 1^{\text {flox/flox }}\right.$ and $\left.W t 1^{-1 f l o x}\right)$ and $W t 1^{-}$ Iflox; Cre-ER ${ }^{T M}$ gonads were dissected at E13.5 and cultured in vitro for 3 days. MVH/SYCP3 (A-D) and MVH/ $\gamma \mathrm{H} 2 \mathrm{AX}(\mathrm{E}-\mathrm{H})$ doublestaining experiment was performed, and germ cells were labeled with MVH (green). DAPI (blue) was used to stain the nuclei. The gender of the embryos was confirmed with PCR using Sry primers.

needs further investigation. To further examine whether abnormal differentiation of gonad somatic cell causes germ cell death, TUNEL assay was performed. As shown in Figure 4, a small number of TUNEL-positive cells (green) were observed in both control and Wt1-inactivated gonads, and no significant difference was noted between control and $W t 1^{R 394 W / R 394 W}$ gonads (A-D) or control and $W t 1^{-/ f l o x}$; Cre-ER ${ }^{T M}$ gonads $(\mathrm{E}-\mathrm{H})$. These results indicated that aberrant differentiation of gonad somatic cells does not cause germ cell death.

3.3. The Expression of Meiosis-Associated Genes in Both Male and Female Germ Cells of Wt1-Inactivated Gonads. To test whether the differentiation of germ cells is affected in $\mathrm{WtI}^{-}$ ${ }^{\text {Iflox }}$; Cre-ER ${ }^{T M}$ gonads, the expression of STRA 8 and SYCP3 was examined by immunofluorescence. As shown in Figure 5, STRA8 (A) and SYCP3 (E) proteins were not expressed in germ cells of control males at E13.5. However, both STRA8 (Figure 5B and D) and SYCP3 (Figure 5F and $\mathrm{H})$ signal were detected in germ cells of $W t 1^{-1 f l o x} ; \mathrm{Cre}-E R^{T M}$ male and female gonads at E13.5. The expression pattern resembled that of the control female germ cells (Figure 5C and $G$ ). The mRNA level of meiosis-associated genes was also analyzed by real-time PCR. The expression of Stra8, Sycp3, Dmc1 (a meiosis specific recombinase), and Rec8 (a meiotic cohesin) was similar between male and female $W t 1^{-1 f l o x}$; $C r e-E R^{T M}$ gonads at E13.5, and it was significantly increased compared to the control male gonads (Figure 5I).

Because most $W t 1^{-/ \text {flox }}$; Cre-ER ${ }^{T M}$ embryos died at E14.5 after tamoxifen induction, to examine the meiosis of germ cells at later developmental stage, control and $W t 1^{-1 \text { flox }}$; Cre$E R^{T M}$ gonads with mesonephroi were dissected at E13.5 and cultured in vitro for 3 days. The expression of SYCP3 and $\gamma \mathrm{H} 2 \mathrm{AX}$ (phospho- $\mathrm{H} 2 \mathrm{AX}$ histone) was examined by immunofluorescence. As shown in Figure 6, thread-like
SYCP3 signal was observed in germ cells of the control ovaries and no SYCP3 signal was detected in germ cell of the control testes. The expression of SYCP3 was also detected in germ cells of both $W t 1^{- \text {flox }}$; Cre-ER $R^{T M}$ male and female gonads. However, only scattered SYCP3 foci were noted. The expression of $\gamma \mathrm{H} 2 \mathrm{AX}$ protein which marks DNA double-strand breaks was also detected in germ cells of both Wt1-deficient male and female gonads, but the number of $\gamma \mathrm{H} 2 \mathrm{AX}$-positive germ cells was significantly reduced compared to the control females.

To further confirm the results, the gonads with mesonephroi of control and $W t 1^{R 394 W / R 394 W}$ mice were also dissected at E12.5, cultured in vitro for 3 days, and then subjected to chromosome spreads and immunofluorescence of SYCP3 and $\gamma \mathrm{H} 2 \mathrm{AX}$. In the control female ovaries, most germ cells have progressed to zygotene stage (Figure 7D-F) and a few germ cells were in leptotene (Figure 7A-C). However, in both male (Figure 7M-O) and female (Figure 7G-I) $W t 1^{R 394 W / R 394 W}$ germ cells, meiosis cannot progress beyond leptotene stage.

SYCP3 is a lateral element of synaptonemal complex that forms between two homologous chromosomes. Its localization pattern during meiosis is used to identify cells at different stages of meiotic prophase I. SYCP3 first appears diffusely in the leptotene stage. As meiosis progresses to the zygotene stage, SYCP3 forms line-shaped structure. In late zygotene and pachytene, prominent synapsis marked by SYCP3 is observed [19]. Although SYCP3 protein were expressed in the germ cells of Wt1-inactivated mice, only diffuse signal was observed, suggesting the meiosis is not properly initiated.

In this study, we found that STRA8 and SYCP3 were expressed in the male germ cells of both $W t 1^{R 394 W / R 394 W}$ and $W t 1^{-1 \text { flox }}$; Cre-ER $R^{T M}$ mouse models. A possible reason for this phenomenon is that the Sertoli cell differentiation 


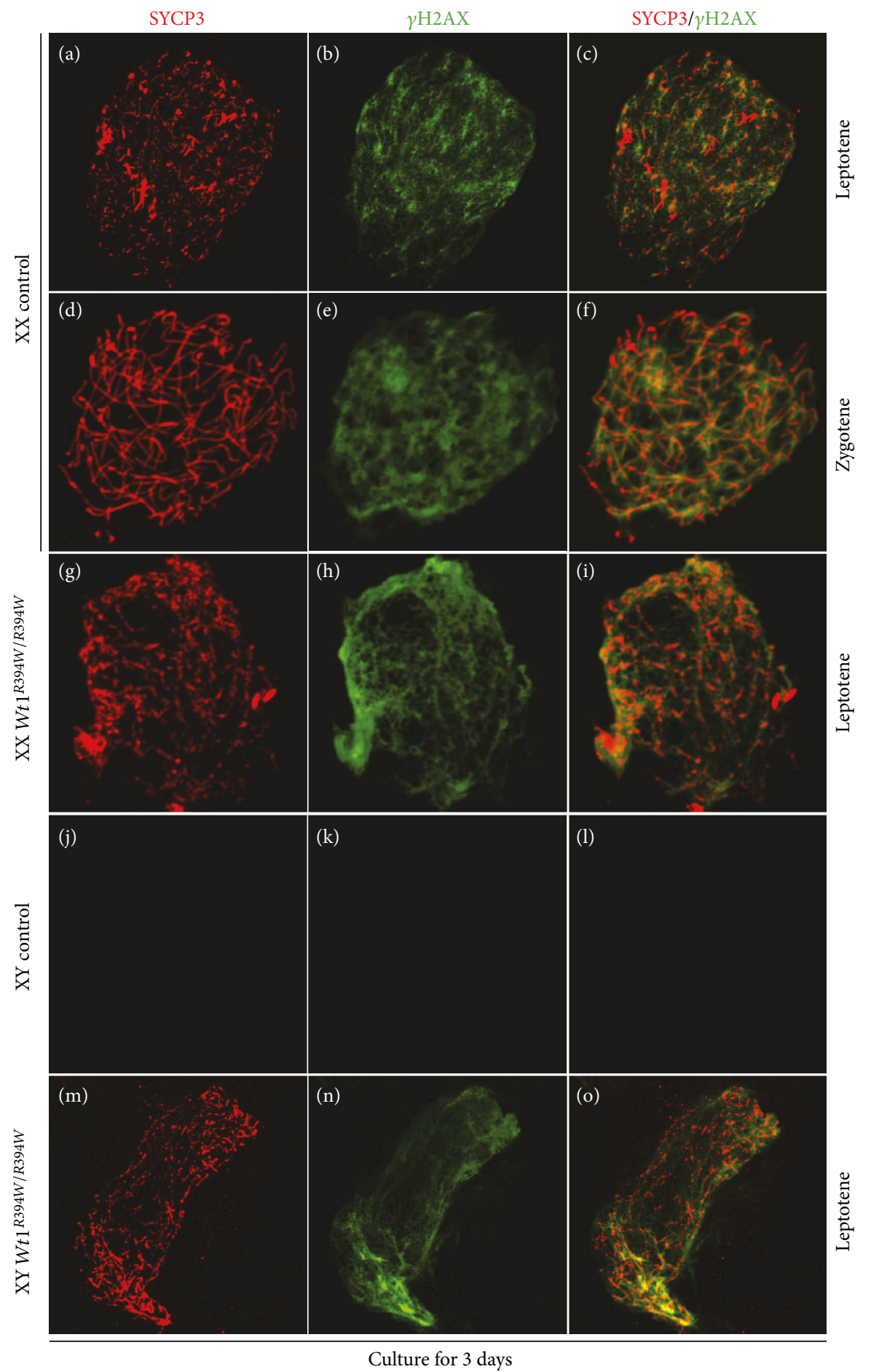

FIGURE 7: Meiosis was blocked at leptotene stage in both male and female germ cells of $W t 1^{R 394 W / R 394 W}$ gonads. Immunofluorescent staining of SYCP3 (red) and $\gamma \mathrm{H} 2 \mathrm{AX}$ (green) were performed on chromosome spreads of control (Wt1 ${ }^{+/ R 394 W}$; A-F: female; J-L: male) and $W t 1^{R 394 W / R 394 W}$ (G-I: female; M-O: male) gonads which were dissected at E12.5 and cultured in vitro for 3 days. The gender of the embryos was confirmed with PCR using Sry primers.

was blocked and no testicular cords were formed in these mouse models. Therefore, the expression of CYP26b1 was decreased and the germ cells would access mesonephrosderived RA, which in turn induced the expression of STRA8 and SYCP3. It has been demonstrated that primordial germ cells at E11.5 are bipotential and they enter meiosis or not depending on the somatic cells [20]. Interestingly, only scattered SYCP3 signals were observed in both male and female germ cells of Wt1-deficient gonads. These results indicate that RA is not sufficient to induce germ cell meiosis initiation and somatic cell environment is also essential for normal meiosis process. 


\section{Conclusions}

Our study demonstrates that aberrant differentiation of somatic cells leads to abnormal meiosis in both male and female germ cells. RA is not sufficient to induce germ cell meiosis initiation, and somatic cell environment is also essential for normal meiosis process.

\section{Data Availability}

The data used to support the findings of this study are included within the article.

\section{Conflicts of Interest}

The authors declare that there is no conflict of interest regarding the publication of this paper.

\section{Authors' Contributions}

Min Chen and Min Chen are co-first authors. In the author list, the two names "Min Chen" reflect two different authors.

\section{Acknowledgments}

This work was supported by the National Key R\&D Program of China (2018YFA0107702); National Science Fund for Distinguished Young Scholars (81525011); Strategic Priority Research Program of the Chinese Academy of Sciences (XDB19000000); and the National Natural Science Foundation of China (31601193 and 31671496).

\section{References}

[1] A. McLaren, "Primordial germ cells in the mouse," Developmental Biology, vol. 262, no. 1, pp. 1-15, 2003.

[2] A. McLaren, "Meiosis and differentiation of mouse germ cells," Symposia of the Society for Experimental Biology, vol. 38, pp. 723, 1984

[3] M. E. Gill, Y. C. Hu, Y. Lin, and D. C. Page, "Licensing of gametogenesis, dependent on RNA binding protein DAZL, as a gateway to sexual differentiation of fetal germ cells," Proceedings of the National Academy of Sciences of the United States of America, vol. 108, no. 18, pp. 7443-7448, 2011.

[4] K. Niederreither, V. Fraulob, J. M. Garnier, P. Chambon, and P. Dolle, "Differential expression of retinoic acidsynthesizing (RALDH) enzymes during fetal development and organ differentiation in the mouse," Mechanisms of Development, vol. 110, no. 1-2, pp. 165-171, 2002.

[5] J. Bowles, D. Knight, C. Smith et al., "Retinoid signaling determines germ cell fate in mice," Science, vol. 312, no. 5773, pp. 596-600, 2006.

[6] C. W. Feng, J. Bowles, and P. Koopman, "Control of mammalian germ cell entry into meiosis," Molecular and Cellular Endocrinology, vol. 382, no. 1, pp. 488-497, 2014.

[7] J. Koubova, D. B. Menke, Q. Zhou, B. Capel, M. D. Griswold, and D. C. Page, "Retinoic acid regulates sex-specific timing of meiotic initiation in mice," Proceedings of the National Academy of Sciences of the United States of America, vol. 103, no. 8, pp. 2474-2479, 2006.
[8] J. F. Armstrong, K. Pritchard-Jones, W. A. Bickmore, N. D. Hastie, and J. B. L. Bard, "The expression of the Wilms' tumour gene, WT1, in the developing mammalian embryo," Mechanisms of Development, vol. 40, no. 1-2, pp. 85-97, 1993.

[9] J. A. Kreidberg, H. Sariola, J. M. Loring et al., "WT-1 is required for early kidney development," Cell, vol. 74, no. 4, pp. 679-691, 1993.

[10] F. Gao, S. Maiti, G. Sun et al., "The $W t 1^{+/ R 394 W}$ mouse displays glomerulosclerosis and early-onset renal failure characteristic of human Denys-Drash syndrome," Molecular and Cellular Biology, vol. 24, no. 22, pp. 9899-9910, 2004.

[11] S. R. Chen, Q. S. Zheng, Y. Zhang, F. Gao, and Y. X. Liu, "Disruption of genital ridge development causes aberrant primordial germ cell proliferation but does not affect their directional migration," BMC Biology, vol. 11, no. 1, p. 22, 2013.

[12] M. Chen, L. Zhang, X. Cui et al., "Wt1 directs the lineage specification of sertoli and granulosa cells by repressing Sf1 expression," Development, vol. 144, no. 1, pp. 44-53, 2017.

[13] J. Martineau, K. Nordqvist, C. Tilmann, R. Lovell-Badge, and B. Capel, "Male-specific cell migration into the developing gonad," Current Biology, vol. 7, no. 12, pp. 958-968, 1997.

[14] T. Sato, K. Katagiri, Y. Kubota, and T. Ogawa, "In vitro sperm production from mouse spermatogonial stem cell lines using an organ culture method," Nature Protocols, vol. 8, no. 11, pp. 2098-2104, 2013.

[15] Q. Zhou, R. Nie, Y. Li et al., "Expression of stimulated by retinoic acid gene 8 (Stra8) in spermatogenic cells induced by retinoic acid: an in vivo study in vitamin A-sufficient postnatal murine testes," Biology of Reproduction, vol. 79, no. 1, pp. 35-42, 2008.

[16] X. Mu, J. Wen, M. Guo et al., "Retinoic acid derived from the fetal ovary initiates meiosis in mouse germ cells," Journal of Cellular Physiology, vol. 228, no. 3, pp. 627-639, 2013.

[17] Y. Lin, M. E. Gill, J. Koubova, and D. C. Page, "Germ cellintrinsic and -extrinsic factors govern meiotic initiation in mouse embryos," Science, vol. 322, no. 5908, pp. 1685-1687, 2008.

[18] F. Gao, S. Maiti, N. Alam et al., "The Wilms tumor gene, Wt1, is required for Sox9 expression and maintenance of tubular architecture in the developing testis," Proceedings of the National Academy of Sciences of the United States of America, vol. 103, no. 32, pp. 11987-11992, 2006.

[19] Y. H. Chi, L. I. Cheng, T. Myers et al., "Requirement for Sun1 in the expression of meiotic reproductive genes and piRNA," Development, vol. 136, no. 6, pp. 965-973, 2009.

[20] N. Nakatsuji and S. Chuma, "Differentiation of mouse primordial germ cells into female or male germ cells," The International Journal of Developmental Biology, vol. 45, pp. 541-548, 2001. 


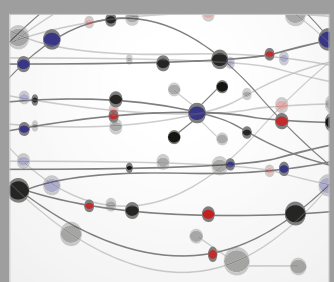

The Scientific World Journal
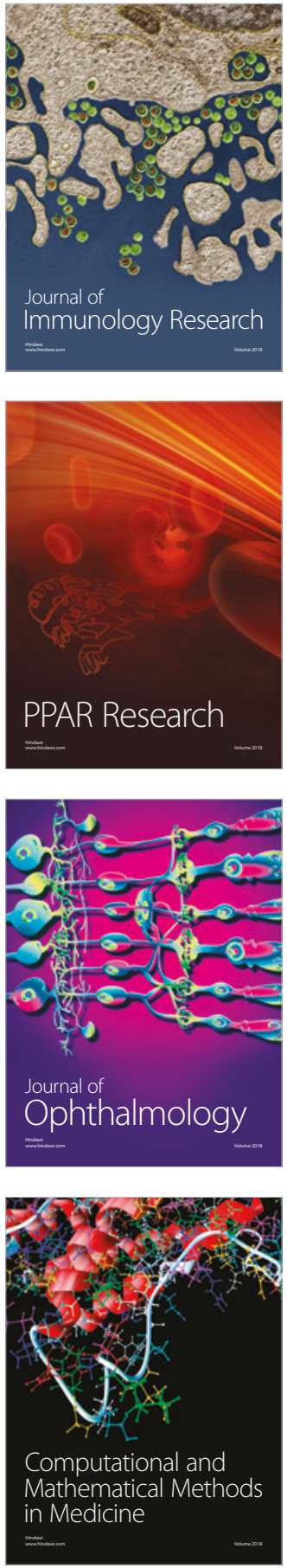

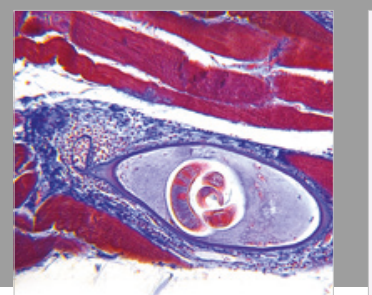

Gastroenterology Research and Practice

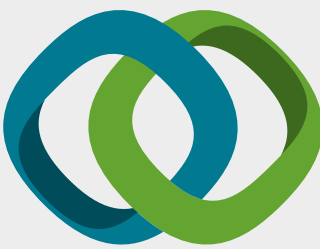

\section{Hindawi}

Submit your manuscripts at

www.hindawi.com
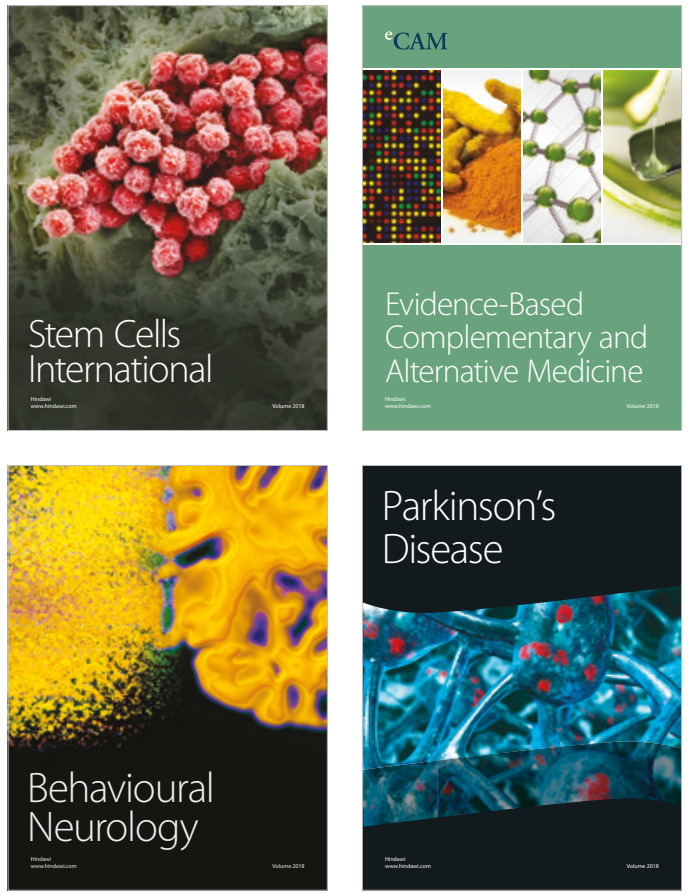

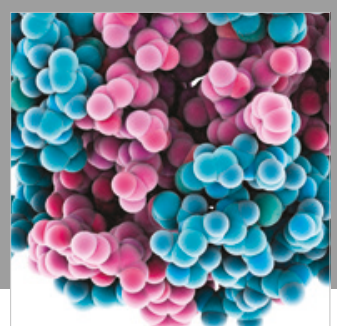

ournal of

Diabetes Research

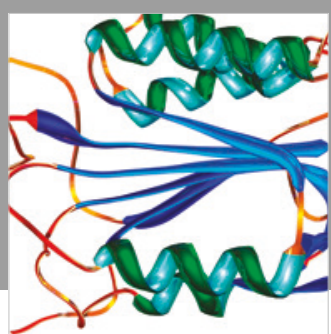

Disease Markers
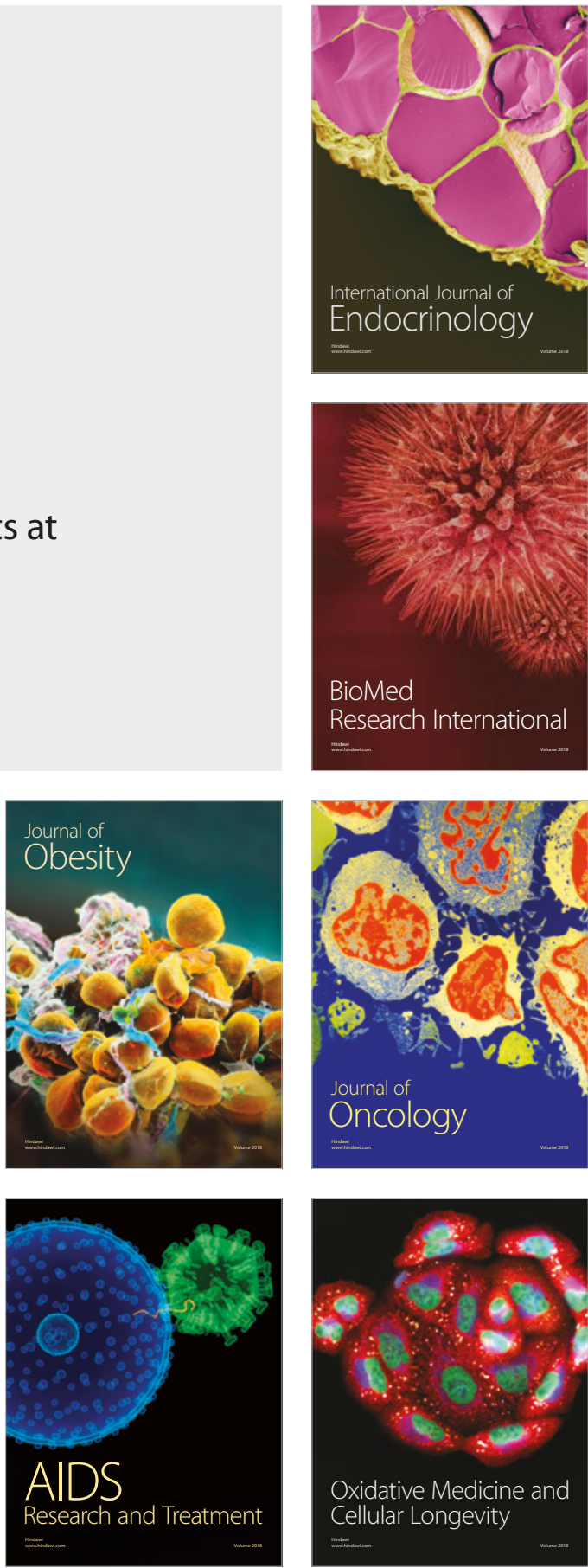